\title{
Article \\ Burned Area Detection Using Multi-Sensor SAR, Optical, and Thermal Data in Mediterranean Pine Forest
}

\author{
Saygin Abdikan ${ }^{1}$ (D), Caglar Bayik ${ }^{2}$ (D) , Aliihsan Sekertekin ${ }^{3, * \mathbb{D}}$, Filiz Bektas Balcik ${ }^{4}$, Sadra Karimzadeh ${ }^{5,6}$, \\ Masashi Matsuoka ${ }^{7}$ (D) and Fusun Balik Sanli ${ }^{8}$ (D)
}

check for

updates

Citation: Abdikan, S.; Bayik, C.;

Sekertekin, A.; Bektas Balcik, F.; Karimzadeh, S.; Matsuoka, M.; Balik Sanli, F. Burned Area Detection Using Multi-Sensor SAR, Optical, and Thermal Data in Mediterranean Pine Forest. Forests 2022, 13, 347. https://doi.org/10.3390/f13020347

Academic Editors: Olga Viedma and Chunying Ren

Received: 31 December 2021

Accepted: 16 February 2022

Published: 18 February 2022

Publisher's Note: MDPI stays neutral with regard to jurisdictional claims in published maps and institutional affiliations.

Copyright: (c) 2022 by the authors. Licensee MDPI, Basel, Switzerland. This article is an open access article distributed under the terms and conditions of the Creative Commons Attribution (CC BY) license (https:/ / creativecommons.org/licenses/by/ $4.0 /)$.
1 Department of Geomatics Engineering, Hacettepe University, Ankara 06800, Turkey; sayginabdikan@hacettepe.edu.tr

2 Department of Geomatics Engineering, Zonguldak Bulent Ecevit University, Zonguldak 67100, Turkey; caglarbayik@beun.edu.tr

3 Department of Architecture, Cukurova University, Adana 01250, Turkey

4 Department of Geomatics Engineering, Istanbul Technical University, Maslak, Istanbul 34469, Turkey; bektasfi@itu.edu.tr

5 Department of GIS and Remote Sensing, University of Tabriz, Tabriz 5166616471, Iran; sa.karimzadeh@tabrizu.ac.ir

6 Remote Sensing Laboratory, University of Tabriz, Tabriz 5166616471, Iran

7 Department of Architecture and Building Engineering, Tokyo Institute of Technology, Yokohama 226-8502, Japan; matsuoka.m.ab@m.titech.ac.jp

8 Department of Geomatic Engineering, Yildiz Technical University, Istanbul 34210, Turkey; fbalik@yildiz.edu.tr

* Correspondence: asekertekin@cu.edu.tr

\begin{abstract}
Burned area (BA) mapping of a forest after a fire is required for its management and the determination of the impacts on ecosystems. Different remote sensing sensors and their combinations have been used due to their individual limitations for accurate BA mapping. This study analyzes the contribution of different features derived from optical, thermal, and Synthetic Aperture Radar (SAR) images to extract BA information from the Turkish red pine (Pinus brutia Ten.) forest in a Mediterranean ecosystem. In addition to reflectance values of the optical images, Normalized Burn Ratio (NBR) and Land Surface Temperature (LST) data are produced from both Sentinel-2 and Landsat- 8 data. The backscatter of C-band Sentinel-1 and L-band ALOS-2 SAR images and the coherence feature derived from the Interferometric SAR technique were also used. The pixel-based random forest image classification method is applied to classify the BA detection in 24 scenarios created using these features. The results show that the L-band data provided a better contribution than C-band data and the combination of features created from Landsat LST, NBR, and coherence of L-band ALOS-2 achieved the highest accuracy, with an overall accuracy of $96 \%$ and a Kappa coefficient of $92.62 \%$.
\end{abstract}

Keywords: forest fire; multi-sensor; random forest; Landsat-8; Sentinel-2; Sentinel-1; ALOS-2

\section{Introduction}

World forests provide environmental, social, and ecological benefits as well as their marketing values. They affect the regional and global climate by means of biological, chemical, and physical processes that influence atmospheric composition, hydrologic cycle, and planetary energetics [1]. In addition to the forests' benefits to the climate, they help all living creatures, especially humankind, by filtering the water, purifying the air, and preventing erosion [2]. Furthermore, forests are home to numerous plants and animals, and they supply fundamental natural resources from timber and food to medicinal plants [3]. However, wildfires affect around 350 million hectares of land annually [4,5], and these fires result in the loss of huge amounts of forest cover. The fundamental causes of forest fires can be categorized into: (i) human activities such as land use land cover (LULC) changes, campfires, smoking, etc., and (ii) natural conditions such as lightning, 
climatic conditions, vegetation status, and topography [6-8]. Over the past five years, the world has witnessed a large number of wildfires, and the responses of the increased fire activities are a rise in fire intensity, changes in climate, reduced moisture availability (dryer summer seasons), higher greenhouse gas emissions, and a loss of various plant and animal species $[9,10]$. Moreover, forest fires have huge impacts on the economy of some countries [11].

After a fire, determining the total affected area, the grade of the damage, and appropriate methods for vegetation rehabilitation are the primary goals of forest management [6]. Spatio-temporal mapping of the burned areas (BAs) is crucial for ecological and environmental impact assessment, determination of economic losses, and nowadays, modeling climatic influences of the burning of biomass $[12,13]$. Therefore, fire management agencies and local governments need timely, accurate/reliable, and cost-effective fire mapping systems, especially under the current situation of the increasing frequency and severity of wildfire events [4,14]. Concerning the BA mapping, Koutsias and Karteris [15] introduced three basic approaches depending on the scale level of measurements, called micro-scale, meso-scale, and macro-scale. The micro-scale level refers to in situ human-made measurements, which are highly accurate but expensive and time-consuming. The meso-scale level represents using aerial photography at a scale ranging from 1:10,000 to 1:25,000. At the macro-scale level, satellite-based remote sensing data with various spatial resolutions starting from 10 meters are used. Satellite imageries with their high spatial and temporal (revisit time) resolutions play an important role in BA mapping, especially in large extent areas with low accessibility. Furthermore, satellite data make it possible to generate continuous and long-term BA databases [16].

Considering the literature, the main remote sensing techniques for BA mapping include supervised and unsupervised classification methods, spectral indices, spectral mixture analysis, logistic regression modeling, principal component analysis, and recently, machine learning $[7,13,15,17-20]$. The datasets used in these methods are generally bitemporal images or single post-fire images. In the bi-temporal approach, the different images obtained pre- and post-fire are used to reveal the differences in the spectral response of the BA. The most commonly used process of the bi-temporal approach includes two steps: (i) spectral index extraction, where popular ones are the Normalized Difference Vegetation Index (NDVI) and Normalized Burn Ratio (NBR), and (ii) different images between preand post-fire indices, namely, dNDVI and dNBR [11,21-24]. Apart from NDVI and NBR, the Mid-Infrared Burned Index (MIRBI), Global Environmental Monitoring Index (GEMI), Burned Area Index Modified (BAIM), and Char Soil Index (CSI) are among the other indices used for BA mapping [25-28]. Specifically, dNBR has been used for burn-severity analysis as the best measure [11,29-31]. Mallinis et al. [30] compared different spectral indices derived from Sentinel-2 and Landsat- 8 for severity analysis in a Mediterranean pine forest. It was concluded that dNBR has a high relationship with field data and Sentinel-2 provided slightly better accuracy of classification. Achour et al. [31] applied dNBR and dNBR-based indices calculated from Sentinel-2 and Landsat- 8 over Tunisia. Similarly, dNBR and the relativized version of it determined good results. It was also concluded that Sentinel-2 was found to be slightly more effective than Landsat- 8 data for BA mapping.

Previous studies revealed the ability of optical, thermal, and radar remote sensing data to be used in BA mappings [4,9,32-35]. The Moderate-Resolution Imaging Spectrometer (MODIS), The Advanced Very High-Resolution Radiometer (AVHRR), and Visible Infrared Imaging Radiometer Suite (VIIRS) are the preliminary sensors used for BA mapping, whose spatial resolutions range between $300 \mathrm{~m}$ and $1 \mathrm{~km}$. Although these sensors have very high temporal resolution (up to two or three revisits in a day), they have low spatial resolutions to present the exact extent of the BA, especially for small extent BAs [33-38]. On the other hand, with their relatively high spatial resolutions but low temporal resolutions, Landsat satellites and Sentinel-2 provide high-quality images for BA mapping at a satisfactory extent $[39,40]$. All of the above instruments provide optical and/or thermal images, and one major drawback of optical and thermal remote sensing is the presence 
of cloud cover, smoke, and/or haze, which is an important limitation for many areas, such as in tropical regions. Therefore, researchers investigated the capability of Synthetic Aperture Radar (SAR) and Interferometric SAR (InSAR) data for mapping the BA since the active microwave has the ability to penetrate through the cloud coverage and it is less affected by weather conditions [4,32,41-43]. Moreover, some studies considered a multi-sensor approach using SAR and optical/thermal data for BA mapping [4,33,44,45]. Philipp and Levick [10] compared Sentinel-2 and Sentinel-1 mapping results of fire scar over tropical savannas. Stroppiana et al. [33] integrated backscatter of C-band ENVISAT data with Landsat TM data to extract burned and unburned regions. Zhang et al. [4] used backscatter, coherence, and reflectance of Sentinel-2 data for the BA mapping. Liu et al. [23] combined the Land Surface Temperature (LST) of Landsat- 8 with the spectral bands to identify the BAs.

The Mediterranean is very vulnerable to fire risk and about $57 \%$ of Turkey's forests are under this risk. Forests in Turkey cover an area of about 22.9 million ha, which is $29 \%$ of the country. Coniferous forest covers $48 \%$, broadleaved covers $32 \%$, and mixed forest covers the remaining $20 \%$. Pinus brutia Ten. is the largest distributed coniferous tree species that covers about $22.74 \%$ of the total amount of forest in Turkey [46]. As a coniferous tree species native to the Mediterranean, Pinus brutia Ten. (Red pine) is located in the western part of the Mediterranean and Pinus Halepensis Mill. (Aleppo pine) is located in the eastern part. Together, they cover an area of approximately 6.8 million hectares in total [47]. They are distributed at the coastal zones where they provide high ecological characteristics. These species are preferred in post-fire afforestation owing to their resistance to dry conditions and their ability to regenerate in a short time. They also have economic importance such as pulp production [46-48]. However, they are also the species most exposed to forest fires in Europe [49]. According to data from the General Directorate of Forestry (OGM), in Turkey, the number of wildfires has increased from around 1000 to around 3500 per year since the 1940s [50]. It is seen that the majority $(\sim 90 \%)$ of the fires that occurred in 2020 and 2019 were human-induced. In 2019, one fire greater than 1000 ha and one of four fires larger than 1000 ha in 2020 occurred in Izmir Region. The number of fires is higher between August and October compared to other months [51,52]. In July and August 2021, $1700 \mathrm{~km}^{2}$ of forest in Turkey's Mediterranean Region was affected by a series of more than two hundred wildfires, meaning the worst-ever wildfire season in the country's history [53]. Therefore, it is crucial for Turkey to determine the accurate extent of the forest fires for post-fire rehabilitation. The major aim of this study is to map BA using multi-sensor data such as SAR data, optical data, and thermal data with the random forest (RA) classifier. SAR data include backscatter images from ALOS-2 and Sentinel-1, and interferometric coherence from ALOS-2. As optical data, reflective bands and spectral indices of Sentinel-2 and Landsat- 8 were implemented, and LST images from the Landsat- 8 Thermal Infrared Sensor (TIRS) were utilized. Twenty-four different scenarios were determined based on these datasets, and as a sub-aim, we investigated the contribution of different sensor data on the accuracy of BA mapping with the use of the RF classifier. To the best of our knowledge, so far, no study has considered such a rich database including SAR backscatter, interferometric coherence, optical data, and thermal data to investigate their effectiveness in BA mapping. In addition to the BA mapping, the burn severity maps were generated from both Sentinel-2- and Landsat-8-derived NBR to reveal the grades of the fire damage, and to compare the results of both sensors.

\section{Materials and Methods}

\subsection{Study Area}

The fire event considered in this study occurred on 18 August 2019 in the district of İzmir metropolitan city (Figure 1). The region where the forest fire was located has a Mediterranean climate. The forest is dominated by coniferous Turkish red pine (Pinus brutia Ten.) and maquis vegetation cover [54]. The elevation ranges from 140 to $975 \mathrm{~m}$. Approximately 5000 ha was affected by the fire [24,54]. 

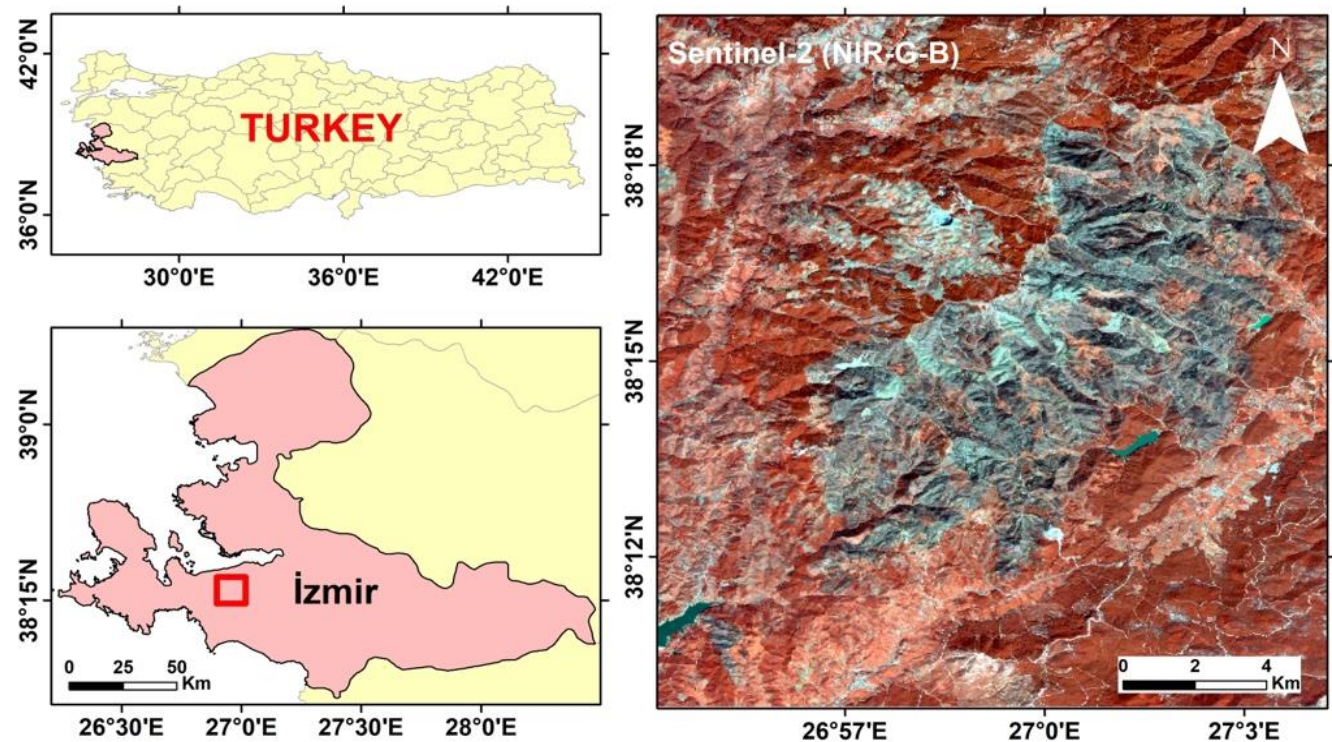

Figure 1. The location of the forest fire. BA is seen in the black patch on the Sentinel-2 image (NIR-G-B) presented in the map on the right.

\subsection{Multi-Sensor Data}

In this study, a multi-sensor approach was proposed to determine the post-fire BA detection. For the analysis, visible, near infrared (NIR), and thermal bands of optical and thermal sensors and multi-frequency SAR data were used (Table 1). The optical satellites, Sentinel-2 and Landsat-8, of pre- and post-fire images were acquired from the archives of ESA (https:/ / scihub.copernicus.eu/) (accessed on 1 September 2021) and NASA (https: / / earthexplorer.usgs.gov/) (accessed on 1 September 2021). Similarly, pre- and postfire images of C-band Sentinel-1(https:/ / scihub.copernicus.eu/) (accessed on 1 September 2021)and L-band ALOS-2 data were used as SAR images. As the time difference between pre- and post-event acquisitions of ALOS-2 data includes a long period, the same acquisition period was also preferred for the other datasets. Different features from optical, thermal, and SAR data were obtained and their contribution to the BA extraction was tested with the RF classification method. A generalized workflow of the study is presented in Figure 2.

Table 1. Multi-sensor remote sensing satellite data specifications used in this study.

\begin{tabular}{|c|c|c|c|c|c|}
\hline Data Type & $\begin{array}{l}\text { Satellite } \\
\text { Mission }\end{array}$ & $\begin{array}{c}\text { Acquisition } \\
\text { Date (Pre-Post) }\end{array}$ & $\begin{array}{c}\text { Image Channel (Band } \\
\text { or Polarization) }\end{array}$ & $\begin{array}{l}\text { Central Wavelength } \\
\text { or Frequency }\end{array}$ & $\begin{array}{c}\text { Spatial Resolution } \\
\text { (m) }\end{array}$ \\
\hline \multirow{11}{*}{ Optical } & \multirow{6}{*}{ Sentinel-2 } & \multirow{6}{*}{$\begin{array}{c}4 \text { March } 2019 \\
13 \text { March } 2020\end{array}$} & Blue (B2) & $492.4 \mathrm{~nm}$ & 10 \\
\hline & & & Green (B3) & $559.8 \mathrm{~nm}$ & 10 \\
\hline & & & Red (B4) & $664.6 \mathrm{~nm}$ & 10 \\
\hline & & & NIR (B8) & $832.8 \mathrm{~nm}$ & 10 \\
\hline & & & Narrow NIR (B8A) & $864.7 \mathrm{~nm}$ & 20 \\
\hline & & & SWIR (B12) & $2202.4 \mathrm{~nm}$ & 20 \\
\hline & \multirow{5}{*}{ Landsat-8 } & \multirow{5}{*}{$\begin{array}{l}16 \text { March } 2019 \\
2 \text { March } 2020\end{array}$} & Blue (B2) & $482 \mathrm{~nm}$ & 30 \\
\hline & & & Green (B3) & $561 \mathrm{~nm}$ & 30 \\
\hline & & & Red (B4) & $655 \mathrm{~nm}$ & 30 \\
\hline & & & NIR (B5) & $865 \mathrm{~nm}$ & 30 \\
\hline & & & SWIR 2 (B7) & $2200 \mathrm{~nm}$ & 30 \\
\hline
\end{tabular}


Table 1. Cont.

\begin{tabular}{|c|c|c|c|c|c|}
\hline Data Type & $\begin{array}{l}\text { Satellite } \\
\text { Mission }\end{array}$ & $\begin{array}{c}\text { Acquisition } \\
\text { Date (Pre-Post) }\end{array}$ & $\begin{array}{c}\text { Image Channel (Band } \\
\text { or Polarization) }\end{array}$ & $\begin{array}{l}\text { Central Wavelength } \\
\text { or Frequency }\end{array}$ & $\begin{array}{l}\text { Spatial Resolution } \\
\text { (m) }\end{array}$ \\
\hline Thermal & Landsat-8 & $\begin{array}{l}16 \text { March } 2019 \\
2 \text { March } 2020\end{array}$ & TIR-1 (B10) & $10,800 \mathrm{~nm}$ & 100 (Resampled to 30) \\
\hline \multirow{4}{*}{ SAR } & \multirow{2}{*}{ Sentinel-1 } & \multirow{2}{*}{$\begin{array}{l}10 \text { March } 2019 \\
4 \text { March } 2020\end{array}$} & VV (C band) & $5.405 \mathrm{GHz}$ & $2.33 \times 13.91(\mathrm{r} \times \mathrm{az})$ \\
\hline & & & $\mathrm{VH}$ (C band) & $5.405 \mathrm{GHz}$ & $2.33 \times 13.91(\mathrm{r} \times \mathrm{az})$ \\
\hline & \multirow{2}{*}{ ALOS-2 } & \multirow{2}{*}{$\begin{array}{l}10 \text { March } 2019 \\
8 \text { March } 2020\end{array}$} & HH (L band) & $1.2 \mathrm{GHz}$ & $4.29 \times 3.41(\mathrm{r} \times \mathrm{az})$ \\
\hline & & & HV (L band) & $1.2 \mathrm{GHz}$ & $4.29 \times 3.41(\mathrm{r} \times \mathrm{az})$ \\
\hline
\end{tabular}

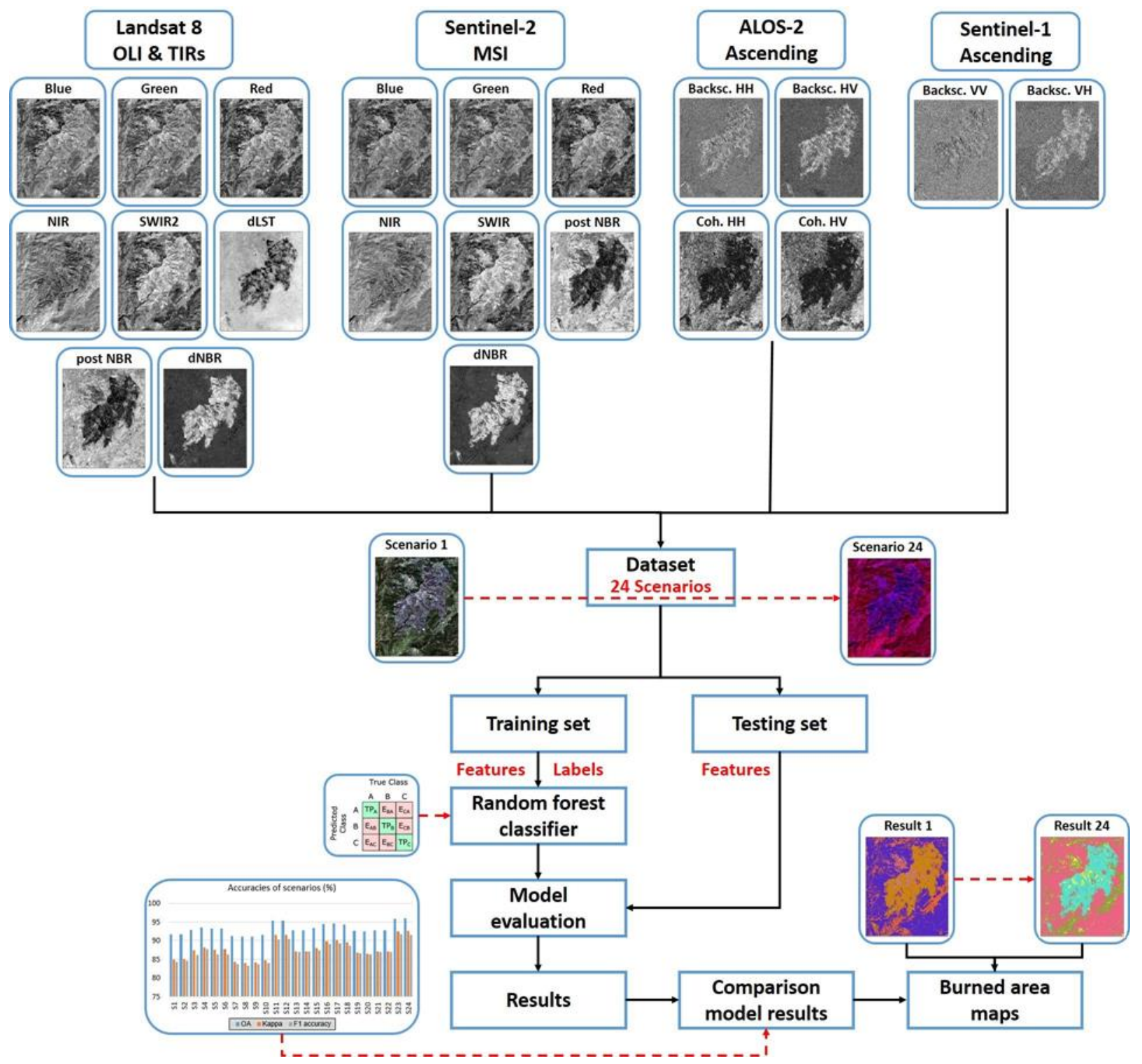

Figure 2. Workflow of the study.

\subsection{Burn Severity Spectral Indices of Optical Images}

Remote sensing-based burn severity indices have been developed and used due to their simple computation and direct application [55]. Spectral indices based on the Near Infrared (NIR) and Short-Wave Infrared (SWIR) bands, specifically the Normalized Burn 
Ratio (NBR) and its bi-temporal approach, such as the differenced Normalized Burn Ratio (dNBR), have been identified as one of the optimal burn severity measures [56,57].

In this study, to determine the burn severity of the selected region, NBR and dNBR were calculated by using pre- and post-fire Landsat-8 OLI and Sentinel-2 MS data (Table 2). BA severity can be easily classified by the dNBR index. The dNBR is obtained by using the bi-temporal difference of the preprocessed NBR images [29].

Table 2. Burn severity spectral indices.

\begin{tabular}{cccc}
\hline Spectral Index & Landsat-8 OLI Equation & Sentinel-2 MSI Equation & Reference \\
\hline NBR & (B5 - B7) /(B5 + B7) & (B8A - B12)/(B8A + B12) & Key and Benson [50] \\
dNBR & (NBRpre-NBRpost) & (NBRpre-NBRpost) & Miller and Thode [49] \\
\hline
\end{tabular}

Hypothetically, the values for $\mathrm{dNBR}$ are between -2 and +2 , where the values for BAs are ranging from 0.10 to 1.35 and the unburned areas from -0.10 to +0.10 in most areas, but the minimum and maximum values can be different based on the study area (Table 3) [58]. These ranges are flexible and scene-pair-dependent, and shifts in thresholds $( \pm 0.1)$ are possible. $d N B R$ values of less than about -0.55 , or greater than about +1.35 may occur, but usually are not considered burned. Rather, they are likely anomalies caused by miss-registration, clouds, or other factors not related to real land cover differences.

Table 3. Burn severity levels obtained by calculating dNBR, proposed by [59].

\begin{tabular}{cc}
\hline Severity Level & dNBR Range (Not Scaled) \\
\hline Unburned & $<-0.1$ \\
Low Severity & $0.1-0.26$ \\
Moderate Low Severity & $0.27-0.43$ \\
Moderate High Severity & $0.44-0.65$ \\
High Severity & $>0.66$ \\
\hline
\end{tabular}

\subsection{LST Extraction}

LST images were obtained from the Landsat-8 TIR-1 band using the Mono Window Algorithm (MWA) proposed by Qin et al. [60]. As the Land Surface Emissivity (LSE) model in LST algorithm, we considered the NDVI threshold-based model introduced by Sobrino et al. [61] since a previous LST accuracy assessment study provided the highest results with Landsat- 8 by this combination [62]. A difference LST (dLST) is created using the difference between pre- and post-fire Landsat- 8 data.

\subsection{Preprocessing of SAR Images}

The Interferometric Wide (IW) mode Sentinel-1 and Strip Map (SM) mode ALOS-2 data were acquired in Single-Look Complex (SLC) image format. For each data point, the backscatter value was obtained after calibration, filtering by the $5 \times 5$ Lee filter and geometric correction with the Shuttle Radar Topography Mission (SRTM) digital elevation model $(30 \mathrm{~m})$. The calibration step converts the digital number of the pixels $\left(D N_{i}\right)$ into the backscattering coefficient $\left(\sigma_{p q}^{0}\right)$. In the below equations, $\mathrm{K}$ is the calibration constant and $\sigma_{p q}^{0}$ is the backscattering coefficient, also called Sigma Nought. The backscattering coefficients which have linear units were converted into decibel $\left(\sigma_{d B}^{0}\right)$ units using Equation (3). A differential image was created to identify the BAs using pre-event backscatter $\left(\sigma_{\text {pre-fire }}\right)$ and post-event backscatter $\left(\sigma_{\text {post-fire }}\right)$ values for each polarimetry. All images were resampled to a common geometric resolution of $30 \mathrm{~m}$.

$$
\begin{aligned}
& \sigma_{p q}^{0}=K \cdot D N_{i}^{2} \\
& \sigma_{p q}^{0}=\frac{\left|D N_{i}\right|^{2}}{A_{i}^{2}}
\end{aligned}
$$




$$
\begin{gathered}
\sigma_{d B}^{0}=10 \cdot \log _{10}\left(\sigma_{p q}^{0}\right) \\
d \sigma_{d B}^{0}=\sigma_{\text {pre-fire }}-\sigma_{\text {post-fire }}
\end{gathered}
$$

As the SAR data were collected in the complex image format, the SLC images have both phase and amplitude information. Using two co-registered SLC images, a cross-correlation factor between the pairs can be extracted with using Equation (5):

$$
\gamma=\frac{\left|\left\langle S_{1} S_{2}^{*}\right\rangle\right|}{\sqrt{\left(\left\langle S_{1} S_{1}^{*}\right\rangle\left\langle S_{2} S_{2}^{*}\right\rangle\right)}}
$$

where $\gamma$ represents coherence, $S_{1}$ and $S_{2}$ represent complex matrices of the backscatter coefficient of the pre- and post-SAR images, ${ }^{*}$ indicates complex conjugation, « indicates spatial averaging, and I I indicates the absolute value $[63,64]$. The coherence values range between zero (low coherence) and one (high coherence). Low coherence indicates a high degree of variation between repeat-pass SAR data. Coherence of Sentinel-1 data was not used further because its values were also very low for non-burned regions. The open-source tools of the Sentinel Application Platform [65] software were used for the preprocessing steps of the SAR data.

\subsection{Land Cover Classification}

The supervised pixel-based RF classification approach, which represents robust performance [66], was used to detect land cover classes, namely, burned forest, unburned forest, agriculture, and bare land. The general information of RF has been provided extensively in several studies $[67,68]$. In brief, the RF approach is mainly a bagging algorithm that adds the randomness feature to the model.

The RF algorithm is based on the creation of many decision trees, combining them to obtain more accurate and reliable results. It uses a series of binary decision trees and it branches each node by using the best among the randomly selected variables at each node. The Information Gain Rate criterion and the Gini Index are the attribute selection measures most frequently used to induce the decision tree. We chose the Gini Index, which measures the impurity of an attribute in relation to the classes. For a given $\mathrm{T}$ training set, it randomly selects a case (pixel) and determines the class that it belongs to. In this work, the optimal number of the trees in the RF classification was applied as 100. This number was determined based on the trial-and-error method, and only this number was used in each scenario to ensure the consistency of the research.

The initialization of a supervised classification process requires composite images and training samples (polygons). The training polygons selected for four classes as BAs, unburned areas, agriculture, and bare land in the composite images were used to classify the images. Training $(n=66)$ and testing $(n=50)$ samples were collected randomly on high-resolution images of Google Earth. The number of training pixels were 965, 3660, 546, and 371 for burned forest, unburned forest, agriculture, and bare land, respectively. The number of test pixels were 678, 2344, 388, and 242 for burned forest, unburned forest, agriculture, and bare land, respectively.

A total of 24 scenarios were described to perform the contribution of different features to extract the fire BAs (Table 4). For this purpose, each feature was added as an additional band to the multispectral bands and their contribution was examined. As a last step, only contributing features were added to identify the contribution of these features to the BA analysis. The resulting BA maps were evaluated with an error matrix using test samples [68]. The EnMap-Box integrated to QGIS was used for the classification and evaluations [69-71]. 
Table 4. The scenarios created for the comparison. S-2 = post-fire Sentinel-2 data, L- $8=$ Landsat- 8 , A-2 = ALOS-2, S- $1=$ Sentinel- $1, \gamma=$ coherence, $d \sigma^{0}=$ backscatter difference.

\begin{tabular}{|c|c|c|c|}
\hline Scenarios & Features & Scenarios & Features \\
\hline S1 & S-2 (B2, B3, B4, B8, B12) & S13 & L-8 (B2, B3, B4, B5, B7) \\
\hline S2 & S-2 (B2, B3, B4, B8, B12), S-2 NBR2020 & S14 & L-8 (B2, B3, B4, B5, B7), L-8 NBR2020 \\
\hline S3 & S-2 (B2, B3, B4, B8, B12), dNBR & S15 & L-8 (B2, B3, B4, B5, B7), dNBR \\
\hline S4 & S-2 (B2, B3, B4, B8, B12), dLST & S16 & L-8 (B2, B3, B4, B5, B7), dLST \\
\hline S5 & $\mathrm{S}-2(\mathrm{~B} 2, \mathrm{~B} 3, \mathrm{~B} 4, \mathrm{~B} 8, \mathrm{~B} 12), \mathrm{A}-2 \gamma_{H V}$ & S17 & $\mathrm{L}-8(\mathrm{~B} 2, \mathrm{~B} 3, \mathrm{~B} 4, \mathrm{~B} 5, \mathrm{~B} 7), \mathrm{A}-2 \gamma_{H V}$ \\
\hline S6 & $\mathrm{S}-2(\mathrm{~B} 2, \mathrm{~B} 3, \mathrm{~B} 4, \mathrm{~B} 8, \mathrm{~B} 12), \mathrm{A}-2 \gamma_{\mathrm{HH}}$ & S18 & $\mathrm{L}-8(\mathrm{~B} 2, \mathrm{~B} 3, \mathrm{~B} 4, \mathrm{~B} 5, \mathrm{~B} 7), \mathrm{A}-2 \gamma_{H H}$ \\
\hline S7 & $\mathrm{S}-2(\mathrm{~B} 2, \mathrm{~B} 3, \mathrm{~B} 4, \mathrm{~B} 8, \mathrm{~B} 12), \mathrm{A}-2 d \sigma_{H V}^{0}$ & S19 & $\mathrm{L}-8(\mathrm{~B} 2, \mathrm{~B} 3, \mathrm{~B} 4, \mathrm{~B} 5, \mathrm{~B} 7), \mathrm{A}-2 d \sigma_{H V}^{0}$ \\
\hline S8 & $\mathrm{S}-2(\mathrm{~B} 2, \mathrm{~B} 3, \mathrm{~B} 4, \mathrm{~B} 8, \mathrm{~B} 12), \mathrm{A}-2 d \sigma_{H V}^{0}$ & S20 & $\mathrm{L}-8(\mathrm{~B} 2, \mathrm{~B} 3, \mathrm{~B} 4, \mathrm{~B} 5, \mathrm{~B} 7), \mathrm{A}-2 d \sigma_{H V}^{0}$ \\
\hline S9 & $\mathrm{S}-2(\mathrm{~B} 2, \mathrm{~B} 3, \mathrm{~B} 4, \mathrm{~B} 8, \mathrm{~B} 12), \mathrm{S}-1 d \sigma_{V V}^{0}$ & S21 & $\mathrm{L}-8(\mathrm{~B} 2, \mathrm{~B} 3, \mathrm{~B} 4, \mathrm{~B} 5, \mathrm{~B} 7), \mathrm{S}-1 d \sigma_{V V}^{0}$ \\
\hline $\mathrm{S} 10$ & $\mathrm{~S}-2(\mathrm{~B} 2, \mathrm{~B} 3, \mathrm{~B} 4, \mathrm{~B} 8, \mathrm{~B} 12), \mathrm{S}-1 d \sigma_{V H}^{0}$ & $\mathrm{~S} 22$ & $\mathrm{~L}-8(\mathrm{~B} 2, \mathrm{~B} 3, \mathrm{~B} 4, \mathrm{~B} 5, \mathrm{~B} 7), \mathrm{S}-1 d \sigma_{V H}^{0}$ \\
\hline S11 & $\mathrm{S}-2(\mathrm{~B} 2, \mathrm{~B} 3, \mathrm{~B} 4, \mathrm{~B} 8, \mathrm{~B} 12), \mathrm{dNBR}, \mathrm{dLST}, \mathrm{A}-2 d \sigma_{H V}^{0}$ & S23 & $\mathrm{L}-8(\mathrm{~B} 2, \mathrm{~B} 3, \mathrm{~B} 4, \mathrm{~B} 5, \mathrm{~B} 7), \mathrm{dNBR}, \mathrm{dLST}, \mathrm{A}-2 d \sigma_{H V}^{0}$ \\
\hline S12 & $\mathrm{S}-2(\mathrm{~B} 2, \mathrm{~B} 3, \mathrm{~B} 4, \mathrm{~B} 8, \mathrm{~B} 12), \mathrm{dNBR}, \mathrm{dLST}, \mathrm{A}-2 d \sigma_{H H}^{0}$ & S24 & $\mathrm{L}-8(\mathrm{~B} 2, \mathrm{~B} 3, \mathrm{~B} 4, \mathrm{~B} 5, \mathrm{~B} 7), \mathrm{dNBR}, \mathrm{dLST}, \mathrm{A}-2 d \sigma_{H H}^{0}$ \\
\hline
\end{tabular}

Accuracy assessments of all of the classification results were calculated to determine the performance of the selected sensors and created scenarios by using the error matrix.

Overall accuracy (OA), user's accuracy (UA), and producer's accuracy (PA), the Kappa coefficient [72], and the F1-score were calculated to assess the performance of the random forest classification. The F1-score provides an accuracy that combines the UA and PA [73]. Google Earth images were used to collect a validation dataset to determine the accuracy of the classification results.

\section{Results}

The contribution of different features derived from multi-sensors was evaluated with the comparison of the accuracy analysis (Figures 3 and 4). In general, all scenarios provided an OA higher than $91 \%$, a Kappa value higher than $83.9 \%$, and an F1 value higher than $83 \%$. In the first twelve scenarios, post-fire Sentinel-2 with VIS and NIR bands were combined with features derived from Sentinel-2 (NBR2020, dNBR), Landsat-8 (dLST), and SAR images (Table 4). The dNBR improved the accuracy better than the index of S-2 NBR2020. The backscattering coefficients of ALOS-2 and Sentinel- 1 could not improve the accuracy, but coherence of ALOS-2 enhanced the accuracy by $1.64 \%$. Including features of optic and SAR images, the OA and Kappa were improved by $3.78 \%$ and $6.62 \%$, respectively, by $\mathrm{S} 12$.

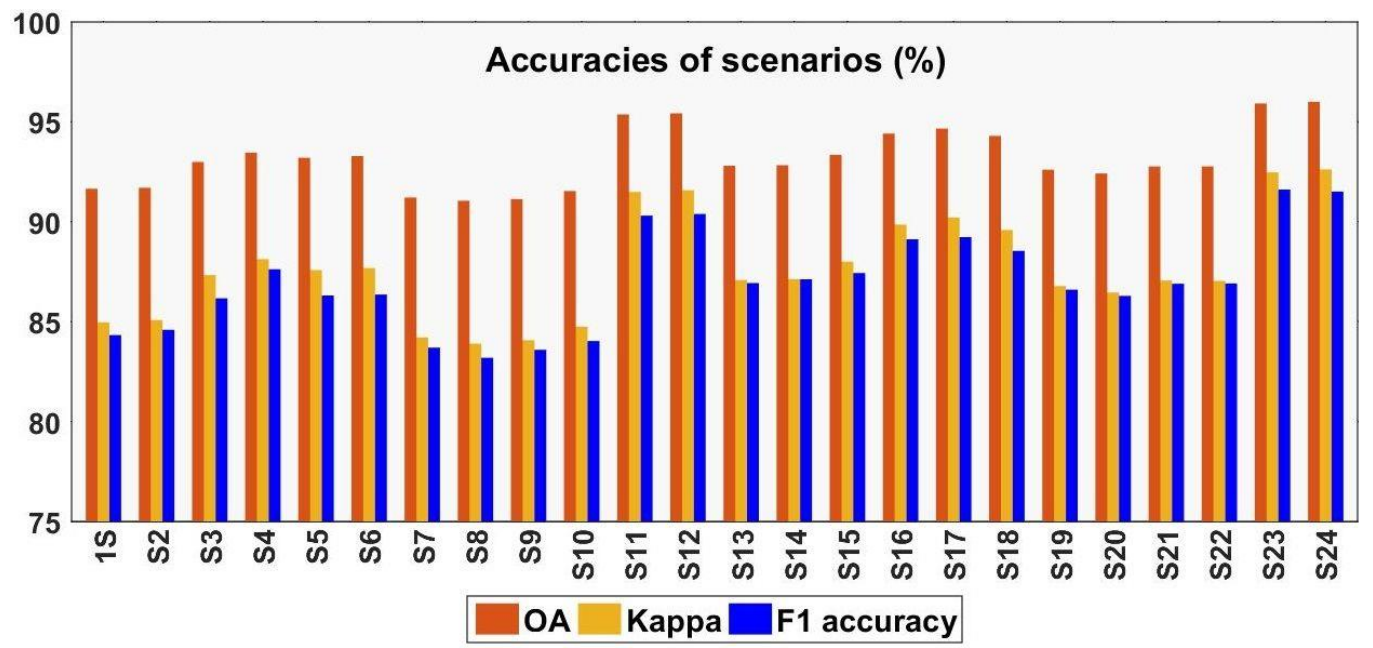

Figure 3. Accuracies of the scenarios (\%) (the details are presented in Appendix A Table A1). 


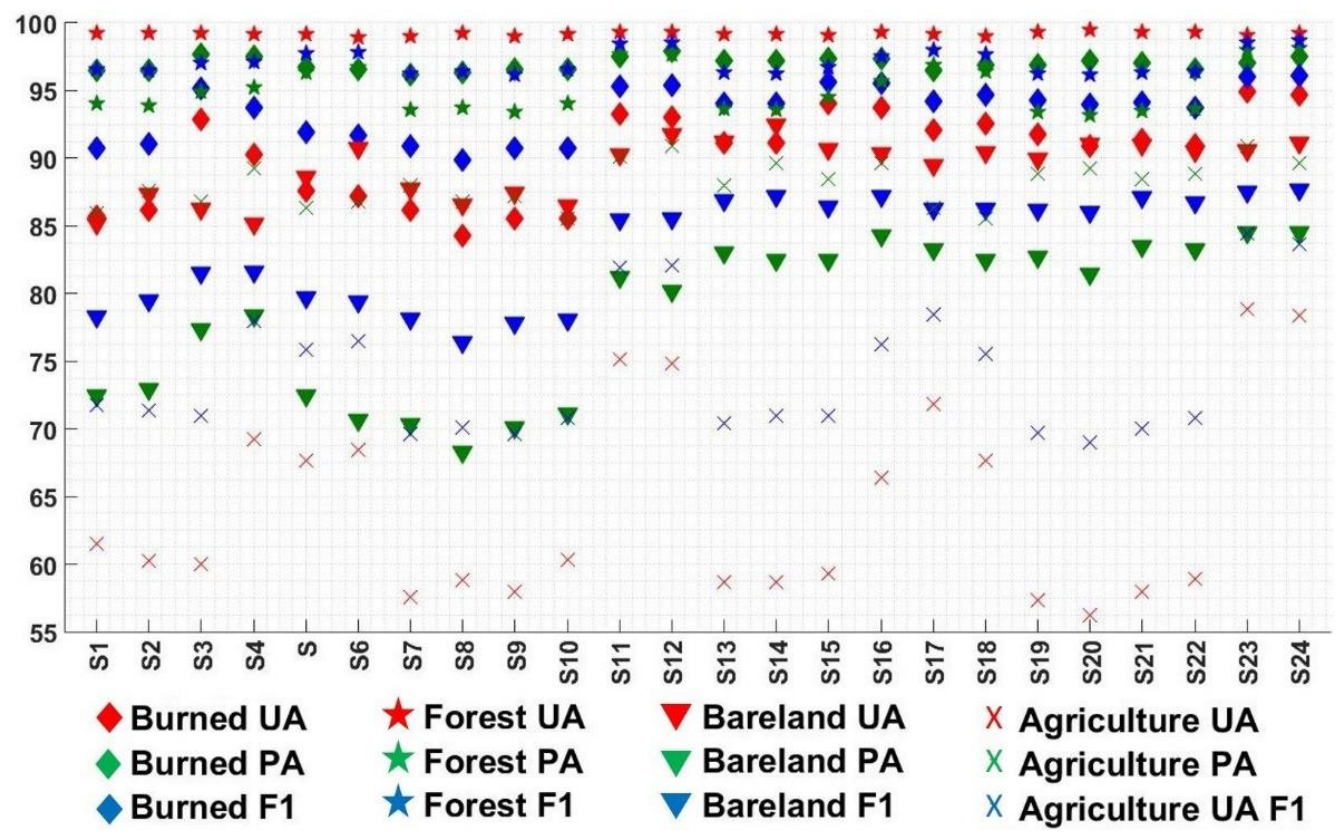

Figure 4. User accuracy (UA) and producer accuracy (PA) of each class (the details are presented in Appendix A Table A2).

Similar to Sentinel-2, the dNBR improved the accuracy better than L-8 NBR2020 when combined with Landsat-8. Both dB values of ALOS-2 and Sentinel-1 could not contribute to the S13. However, similar to Sentinel-2, Landsat- 8 combined coherence improved the results. The combination of all data (S24) provided an increase of $3.2 \%$ in the OA and $5.54 \%$ in the Kappa values. Including dLST and coherence of ALOS-2, the results slightly improved the UA from $92.85 \%$ to $93.23 \%$ and decreased the PA from $97.64 \%$ to $97.49 \%$. Landsat- 8 increased the UA of BA by $3.8 \%$. S24 provided the highest PA and F1 among all scenarios (Figure 5).

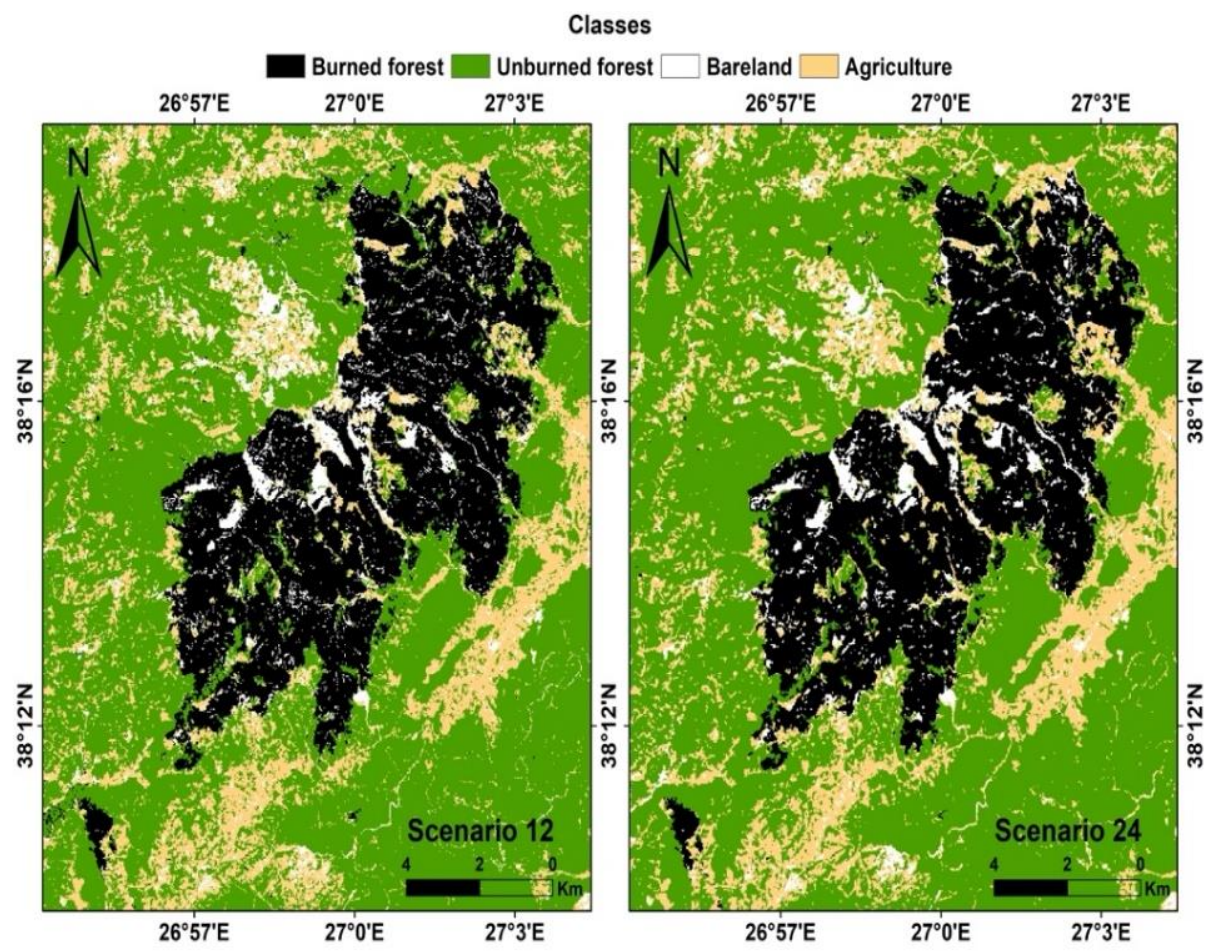

Figure 5. The highest classification accuracy results of scenarios using Sentinel-2 (S12) and Landsat-8 (S24). 
The highly accurate classification results which were provided by the S12 and S24 are mapped in Figure 5. When comparing the contributions of the Sentinel-2 and Landsat-8 combined datasets, it showed that the results have similarity and the two sensors confirmed each other. The highest accuracy obtained with S24 indicates that the BA was found to be about 5742 ha. About $97 \%$ of the BA was covered with Turkish Red pine forest. The results of the burn severity analysis showed that the BA is mostly covered with moderate- to high-severity levels and Sentinel-2 data provided higher severity regions (3107.87 ha) than Landsat-8 data (1292.42 ha). The moderate-high-severity levels of Sentinel-2 (2066.87 ha) are closer to the result of Landsat-8 (2447.33 ha) (Figure 6).

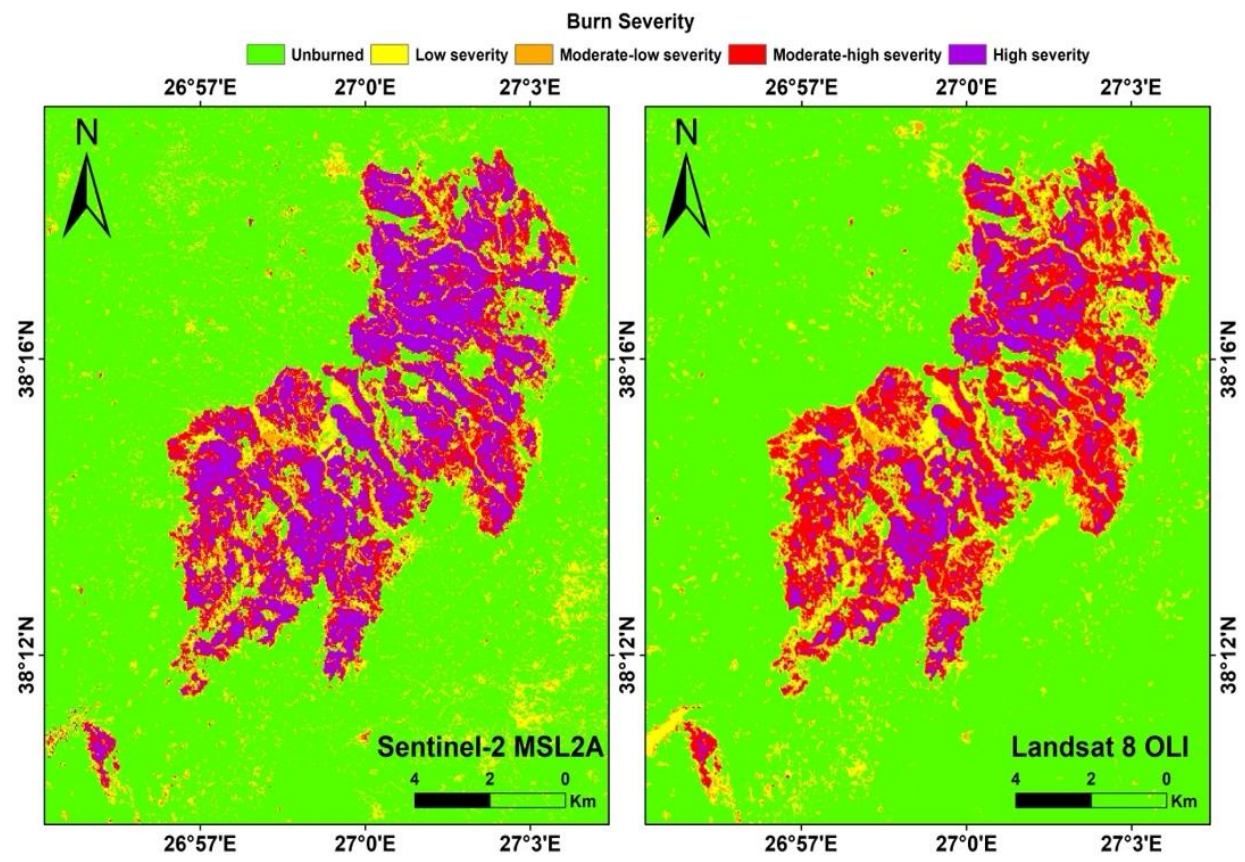

Figure 6. Burn severity maps derived from Sentinel-2 and Landsat-8.

The severity map was analyzed with a slope map that was derived from ALOS World $3 \mathrm{D}$ [74]. The data have $30 \mathrm{~m}$ spatial resolution. The overlapped region was divided to five classes of slope, as gentle $\left(0^{\circ}-5^{\circ}\right)$, low $\left(5^{\circ}-15^{\circ}\right)$, medium $\left(15^{\circ}-25^{\circ}\right)$, high $\left(25^{\circ}-35^{\circ}\right)$, and steep $\left(>35^{\circ}\right)$. In places where the slope is close to flat, it was seen that the severity of the fire was low, and as the slope increases to a medium degree, the severity of the fire also increased. On the contrary, it was determined that the burn severity decreased from moderate to steep slopes in both cases (Figure 7).
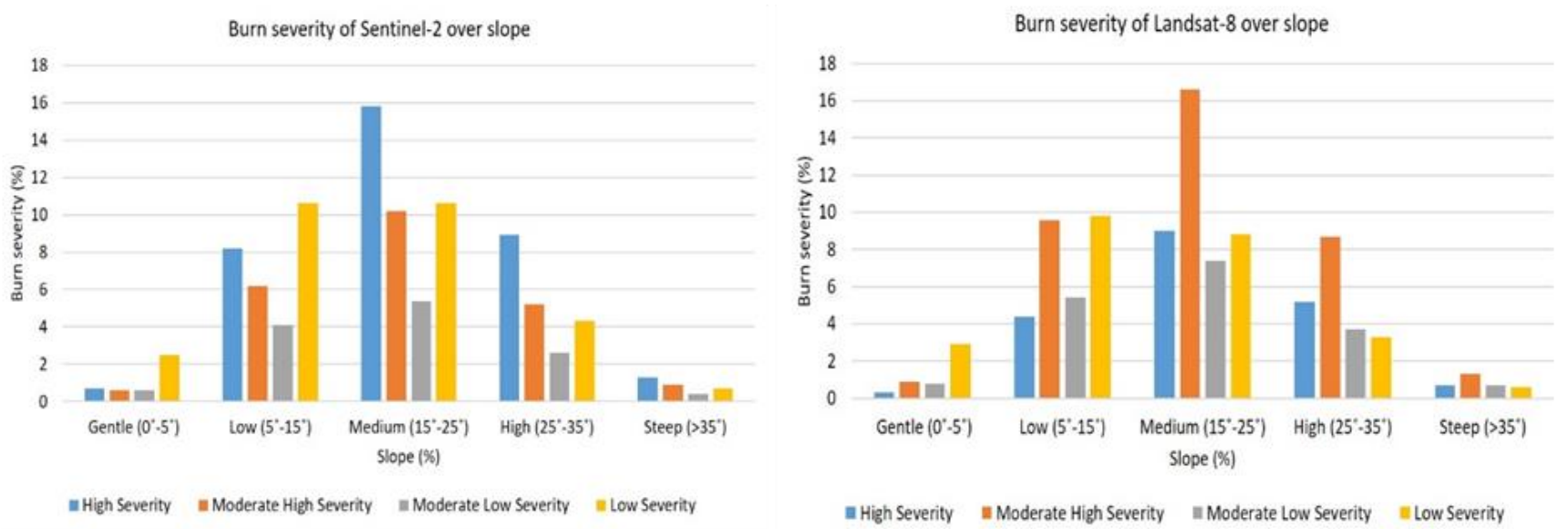

Figure 7. Spatial analysis of burn severity over slope. 


\section{Discussions}

The spectral indices of optical images have been widely used for BA extraction. In addition to different indices derived from individual satellites [75], the combination of backscatter of SAR and indices derived from optical data [33], the combination of backscatter, coherence, and reflectance of Sentinel-2 [4], and the combined approach of LST of Landsat-8 with the spectral bands improved BA mapping [23]. While other studies indicated success of coherence data, Philipp and Levick [10] failed to add a contribution compared to backscatter data.

In this study, different from the above-mentioned studies, spectral bands of optical data, spectral indices, and LST were combined with SAR features to improve the accuracy of BA detection. Among all of the features, dLST and ALOS-2 individually contributed more than the other features. Only using NBR2020 (S2 and S14) presented almost similar results to the results of Sentinel-2 (S1) and Landsat-8 (S13). The contribution of $\mathrm{NBR}_{2019}$ could be seen when dNBR was added to the reflectance data. While considering the polarimetry, it was noticed that each $\sigma_{d B}^{0}$ (bakscatter difference) of polarimetric data could not contribute to the classification accuracy and the OA was decreased.

In general, the results of Sentinel-2 (S1 to S12) and L-8 (S13 to S24) showed that Landsat8 provided slightly higher accuracies than Sentinel-2. Considering the class of burned forest, the accuracies were close to each other, which is similar to the spatial distribution pattern of burned areas in two products (S12 and S24). The results showed that the scenario combined with Sentinel-2 (S12) detected a slightly higher BA (5813 ha) than the scenario combined with Landsat-8 (S24) (5742 ha). The BA of Turkish Red pine was about 98\%, whereas 10\% was degraded forest in both results. The rest is composed of agriculture ( $\sim 5$ ha in S12 and $\sim 50$ ha in S24) and maquis ( $~ 59$ ha in S12 and $\sim 60$ ha in S24). Ngadze et al. [40] compared RF classified Sentinel-2 and Landsat- 8 images over two areas and showed that Sentinel-2 had higher accuracies on one site while Landsat- 8 accuracy was higher on the other site. They report that the reason for their result may be due to the acquisition periods of the satellite images. In our case, there was also a time difference between the two satellite image acquisitions. Another reason might also be due to the up-sampling of Sentinel-2 images to Landsat-8 resolution. When comparing bands, the thermal band added scenarios (S4 and S16) had higher contributions than scenarios with a combination of NIR and SWIR bands (S1 and S13), as seen in both Sentinel-2 and Landsat-8 datasets.

Differences between wavelengths showed that L-band ALOS-2 data illustrated a higher change after the fire compared to C-band Sentinel-1 data. The value of $\sigma_{d B}^{0}$ represents the sum of the intensity collected by the sensor after backscattering. The $\gamma$ (coherence) presents the direct measurement of distributed scatters obtained by the phase information using SAR interferometry [9]. As coherence is widely affected by the temporal decorrelation pre- and post-fire, the SAR pair should provide low coherence at the BA compared to the unburned forest area. However, Sentinel-1 did not show a low-level coherence value at the burned region and it was not included in the processing. On the other hand, ALOS-2 data provided a high level of coherence loss, which added a contribution to discriminate the BA. Tanase et al. [9] showed that the sensitivity of L-band ALOS-1 data is higher than other bands when using almost one and a half month acquisition periods over the pine forest of Spain. In our study, even though the temporal acquisition periods were almost one year, the coherence of L-band ALOS-2 for both cross- and co-polarized data indicated a sensitivity to determine BA over the Turkish red pine-dominated forest region. Sentinel-1 showed limitations for the extraction of BA over a one-year image pair acquisition. Compared to the short-wavelength C-band, the longer wavelength L-band indicated higher coherence even when the temporal baseline was about one year. However, the backscatter of ALOS-2 could not improve the accuracies when it was included.

The burn severity analysis using dNBR showed that Sentinel-2 resulted in a higher level of severity compared to the Landsat- 8 data. The differences between the two severity maps might be due to the differences in image acquisition periods and the spatial resolutions [30]. The burn severity and its distribution on different slope levels showed that 
Sentinel- 2 and Landsat- 8 provided similar trends: $42 \%$ and $41.8 \%$ of burn severity were located over the medium slope using Sentinel-2 and Landsat-8, respectively.

The study area was also analyzed by the previous studies that focused on merely optical datasets. Nasery and Kalkan [76] used Sentinel-2 data with dNBR and dSAVI indices to assess the burn severity. The results indicated that the dNBR index provided better discrimination of severity levels than dSAVI. However, the detected BA using both indices (dNBR $\sim 6910$ ha, dSAVI $\sim 6700$ ha) was not closer to the reference area ( $\sim 5000 \mathrm{ha})$ presented in the previous studies [24,54].

Atak and Tonyaloglu [54] evaluated five indices, namely, dNDVI, dARVI, dBAI, $\mathrm{dNBR}$, and dNBR2, calculated from the pre- and post-fire images of L-8. An object-based classification was applied to detect burned and unburned regions using S-2 data as the reference data. The results indicated that dNDVI achieved the closest area ( 6204 ha) that was detected, however $\mathrm{dNBR} 2$ and $\mathrm{dARVI}$ provided the best results of classification accuracy, with an OA of $84 \%$, a UA of $90 \%$, and a PA of $90 \%$ in both indices.

Masshadi and Alganci [24] evaluated four indices, namely dNDVI, dNBR, RdNBR, and RBR, for burn severity mapping derived from both Sentinel- 2 and Landsat- 8 datasets. The RdNBR index presented the highest accuracies in both Landsat- $8(89 \%)$ and Sentinel-2 $(93 \%)$ data with respect to the active fire dataset of NASA. However, the estimated areas were not close to the declared area as the RdNBR results from Sentinel- 2 and Landsat- 8 were $\sim 7979.4$ and $\sim 6669.6$ ha, respectively. The study also applied SVM and RF classification approaches on reflectance images of Sentinel- 2 and Landsat- 8 to extract the BA. The results showed that SVM estimated a larger BA than the RF approach. SVM provided better accuracies $(\mathrm{OA}=89 \%$, Kappa $=0.87)$ compared to $\mathrm{RF}(\mathrm{OA}=86 \%$, Kappa $=0.85)$. However, RF better-estimated the BA using Landsat-8 ( 5722.5 ha) than Sentinel-2 ( 5790.8 ha) data.

Compared to the previous studies over the same region, this study provided a higher OA $(98.92 \%)$ with a multi-sensor approach using the RF method. Masshadi and Alganci [24] estimated a BA slightly closer to the reference area; however, the OA and Kappa accuracies were lower than in this study. This might be due to the different acquisition periods of the optical data. Additionally, the selected and distributed numbers of training and test pixels were not same. In this study, in addition to the major portion of the BA, a small BA located in the south-west direction was also extracted (Figure 5). The previous studies, conducted over the same test site, merely used spectral indices of Sentinel-2 for severity analysis [76] and spectral indices of Sentinel-2 with object-based image classification [54]. In addition, a comparison was applied using spectral indices of Sentinel-2 and Landsat- 8 data and pixel-based classification of spectral bands with SVM and RF methods [24]. As to these previous methods, our study demonstrated that the additional features from different satellite sensors can improve the accuracy of BA extraction using the pixel-based RF method. Concerning the other multi-sensor-based studies about BA mappings, the combination of multispectral and thermal bands of optical data [23], integration of optical and SAR data [33], SAR backscatter, coherence map, and optical spectral information [4] all showed the advantages of multi-sensor analysis. Moreover, in this study, not only the thermal band of optical satellites but also the coherence map of SAR data played an important role when they were combined with multispectral bands of optical data for accurate BA detection. Additionally, spatial analysis was applied to the burn severity map to show the spatial distribution of severity levels at different slopes.

\section{Conclusions}

This study analyzed the performance of different features which were extracted from optical and SAR data over a BA in a Mediterranean coniferous forest. The analysis showed that the use of a thermal band to extract the BA contributed more than the NIR and SWIR bands of optical data. The results also indicated that Sentinel- 2 and Landsat- 8 provided compatible results and they can be used as alternatives of each other.

The long-wavelength L-band SAR data provided a better contribution than C-band SAR data when the InSAR-based coherence feature was considered. The extraction of 
the BA was affected by the long temporal resolution between image acquisitions. L-band ALOS-2 was more sensitive to the changes, and the loss of coherence more clearly showed the changes between pre-fire and post-fire.

The study highlighted the contribution of the combined use of LST and coherence for mapping burnt regions in Mediterranean forests. In addition to optical VNIR bands, we used features derived from optical images, namely NBR, LST, and SAR data, as coherence information, which have not been evaluated all together for forest fire burn analysis in the literature.

Further analysis will focus on features derived from full polarimetric data in combination with optical features to identify the forest reforestation using multi-temporal analysis. The new L-band NISAR mission is expected to contribute to this issue with its short revisit time and open data policy.

Author Contributions: Conceptualization, S.A., C.B., A.S., F.B.B. and F.B.S.; methodology, S.A., C.B., A.S., F.B.B. and F.B.S.; analysis and validation, S.A., C.B., A.S. and F.B.B.; writing-original draft preparation, S.A., A.S. and F.B.B.; writing-review and editing, S.A., C.B., A.S., F.B.B., S.K., M.M. and F.B.S.; visualization, C.B. All authors have read and agreed to the published version of the manuscript.

Funding: This research received no external funding.

Institutional Review Board Statement: Not applicable.

Informed Consent Statement: Not applicable.

Data Availability Statement: The Copernicus Sentinel-1 and Sentinel-2 are openly available on the website of https:/ / scihub.copernicus.eu/, accessed on 1 September 2021. Landsat-8 and ALOS World 3D data used in this study are openly available in the websites of NASA (https:/ / earthexplorer.usgs. gov/, accessed on 1 September 2021) and JAXA (https:/ / www.eorc.jaxa.jp/ALOS/en/dataset/aw3 d30/aw3d30_e.htm, accessed on 1 September 2021), respectively.

Acknowledgments: The authors would like to thank Japan Aerospace Exploration Agency (JAXA), which provided the ALOS-2 data through the JAXA working group and ALOS World 3D data. The authors would like to thank United States Geological Survey (USGS) and the National Aeronautics and Space Administration (NASA) for providing Landsat- 8 images at free of cost. Besides, the authors would like to thank European Space Agency (ESA) for providing Sentinel-1 and Sentinel-2 images freely available.

Conflicts of Interest: The authors declare no conflict of interest.

\section{Appendix A}

Table A1. Accuracy analysis of each scenario. The best result of each accuracy metric is written in bold.

\begin{tabular}{|c|c|c|c|c|}
\hline Scenarios & Features & OA (\%) & Kappa (\%) & F1 Accuracy (\%) \\
\hline S1 & S-2 (B2, B3, B4, B8, B12) & 91.65 & 84.96 & 84.33 \\
\hline S2 & S-2 (B2, B3, B4, B8, B12), NBR2020 & 91.70 & 85.08 & 84.59 \\
\hline S3 & S-2 (B2, B3, B4, B8, B12), dNBR & 92.99 & 87.33 & 86.17 \\
\hline S4 & S-2 (B2, B3, B4, B8, B12), dLST & 93.46 & 88.13 & 87.62 \\
\hline S5 & $\mathrm{S}-2(\mathrm{~B} 2, \mathrm{~B} 3, \mathrm{~B} 4, \mathrm{~B} 8, \mathrm{~B} 12), \mathrm{A}-2 \gamma_{H V}$ & 93.20 & 87.58 & 86.31 \\
\hline S6 & $\mathrm{S}-2(\mathrm{~B} 2, \mathrm{~B} 3, \mathrm{~B} 4, \mathrm{~B} 8, \mathrm{~B} 12), \mathrm{A}-2 \gamma_{H H}$ & 93.29 & 87.68 & 86.36 \\
\hline S7 & $\mathrm{S}-2(\mathrm{~B} 2, \mathrm{~B} 3, \mathrm{~B} 4, \mathrm{~B} 8, \mathrm{~B} 12), \mathrm{A}-2 d \sigma_{H V}^{0}$ & 91.21 & 84.21 & 83.70 \\
\hline S8 & $\mathrm{S}-2(\mathrm{~B} 2, \mathrm{~B} 3, \mathrm{~B} 4, \mathrm{~B} 8, \mathrm{~B} 12), \mathrm{A}-2 d \sigma_{H V}^{0}$ & 91.05 & 83.90 & 83.19 \\
\hline S9 & $\mathrm{S}-2(\mathrm{~B} 2, \mathrm{~B} 3, \mathrm{~B} 4, \mathrm{~B} 8, \mathrm{~B} 12), \mathrm{S}-1 d \sigma_{V V}^{0}$ & 91.13 & 84.07 & 83.59 \\
\hline $\mathrm{S} 10$ & $\mathrm{~S}-2(\mathrm{~B} 2, \mathrm{~B} 3, \mathrm{~B} 4, \mathrm{~B} 8, \mathrm{~B} 12), \mathrm{S}-1 d \sigma_{V H}^{0}$ & 91.54 & 84.75 & 84.03 \\
\hline S11 & $\mathrm{S}-2(\mathrm{~B} 2, \mathrm{~B} 3, \mathrm{~B} 4, \mathrm{~B} 8, \mathrm{~B} 12), \mathrm{dNBR}, \mathrm{dLST}, \mathrm{A}-2 d \sigma_{H V}^{0}$ & 95.37 & 91.49 & 90.31 \\
\hline S12 & $\mathrm{S}-2(\mathrm{~B} 2, \mathrm{~B} 3, \mathrm{~B} 4, \mathrm{~B} 8, \mathrm{~B} 12), \mathrm{dNBR}, \mathrm{dLST}, \mathrm{A}-2 d \sigma_{H H}^{0}$ & 95.43 & 91.58 & 90.39 \\
\hline
\end{tabular}


Table A1. Cont.

\begin{tabular}{|c|c|c|c|c|}
\hline Scenarios & Features & OA (\%) & Kappa (\%) & F1 Accuracy (\%) \\
\hline S13 & L-8 (B2, B3, B4, B5, B7) & 92.80 & 87.08 & 86.93 \\
\hline S14 & L-8 (B2, B3, B4, B5, B7), NBR2020 & 92.83 & 87.13 & 87.12 \\
\hline S15 & L-8 (B2, B3, B4, B5, B7), dNBR & 93.35 & 88.00 & 87.43 \\
\hline S16 & L-8 (B2, B3, B4, B5, B7), dLST & 94.41 & 89.86 & 89.12 \\
\hline S17 & $\mathrm{L}-8(\mathrm{~B} 2, \mathrm{~B} 3, \mathrm{~B} 4, \mathrm{~B} 5, \mathrm{~B} 7), \mathrm{A}-2 \gamma_{H V}$ & 94.66 & 90.21 & 89.23 \\
\hline S18 & $\mathrm{L}-8(\mathrm{~B} 2, \mathrm{~B} 3, \mathrm{~B} 4, \mathrm{~B} 5, \mathrm{~B} 7), \mathrm{A}-2 \gamma_{H H}$ & 94.30 & 89.59 & 88.54 \\
\hline S19 & $\mathrm{L}-8(\mathrm{~B} 2, \mathrm{~B} 3, \mathrm{~B} 4, \mathrm{~B} 5, \mathrm{~B} 7), \mathrm{A}-2 d \sigma_{H V}^{0}$ & 92.61 & 86.78 & 86.60 \\
\hline S20 & $\mathrm{L}-8(\mathrm{~B} 2, \mathrm{~B} 3, \mathrm{~B} 4, \mathrm{~B} 5, \mathrm{~B} 7), \mathrm{A}-2 d \sigma_{H V}^{0}$ & 92.42 & 86.46 & 86.29 \\
\hline S21 & $\mathrm{L}-8(\mathrm{~B} 2, \mathrm{~B} 3, \mathrm{~B} 4, \mathrm{~B} 5, \mathrm{~B} 7), \mathrm{S}-1 d \sigma_{V V}^{0}$ & 92.77 & 87.06 & 86.90 \\
\hline S22 & $\mathrm{L}-8(\mathrm{~B} 2, \mathrm{~B} 3, \mathrm{~B} 4, \mathrm{~B} 5, \mathrm{~B} 7), \mathrm{S}-1 d \sigma_{V H}^{0}$ & 92.77 & 87.04 & 86.91 \\
\hline S23 & $\mathrm{L}-8(\mathrm{~B} 2, \mathrm{~B} 3, \mathrm{~B} 4, \mathrm{~B} 5, \mathrm{~B} 7), \mathrm{dNBR}, \mathrm{dLST}, \mathrm{A}-2 d \sigma_{H V}^{0}$ & 95.92 & 92.47 & 91.61 \\
\hline S24 & $\mathrm{L}-8(\mathrm{~B} 2, \mathrm{~B} 3, \mathrm{~B} 4, \mathrm{~B} 5, \mathrm{~B} 7), \mathrm{dNBR}, \mathrm{dLST}, \mathrm{A}-2 d \sigma_{H H}^{0}$ & 96.00 & 92.62 & 91.51 \\
\hline
\end{tabular}

Table A2. Accuracy analysis of each classes in each scenarios. The best result of each class is written in bold.

\begin{tabular}{|c|c|c|c|c|c|c|c|c|c|c|c|c|}
\hline \multirow[b]{2}{*}{ Scenarios } & \multicolumn{3}{|c|}{ Burned } & \multicolumn{3}{|l|}{ Forest } & \multicolumn{3}{|c|}{ Bareland } & \multicolumn{3}{|c|}{ Agriculture } \\
\hline & UA & PA & F1 & UA & PA & F1 & UA & PA & F1 & UA & PA & F1 \\
\hline S1 & 85.71 & 96.46 & 90.77 & 99.23 & 94.03 & 96.56 & 85.15 & 72.42 & 78.27 & 61.54 & 85.95 & 71.72 \\
\hline $\mathrm{S} 2$ & 86.17 & 96.46 & 91.02 & 99.23 & 93.86 & 96.47 & 87.35 & 72.94 & 79.49 & 60.23 & 87.60 & 71.38 \\
\hline S3 & 92.85 & 97.64 & 95.18 & 99.24 & 94.88 & 97.01 & 86.21 & 77.32 & 81.52 & 60.00 & 86.78 & 70.95 \\
\hline $\mathrm{S} 4$ & 90.30 & 97.49 & 93.76 & 99.16 & 95.22 & 97.15 & 85.15 & 78.35 & 81.61 & 69.23 & 89.26 & 77.98 \\
\hline S5 & 87.58 & 96.76 & 91.94 & 99.17 & 96.33 & 97.73 & 88.64 & 72.42 & 79.72 & 67.64 & 86.36 & 75.86 \\
\hline S6 & 87.22 & 96.61 & 91.67 & 98.95 & 96.76 & 97.84 & 90.73 & 70.62 & 79.42 & 68.40 & 86.78 & 76.50 \\
\hline S7 & 86.13 & 96.17 & 90.87 & 99.05 & 93.56 & 96.23 & 87.78 & 70.36 & 78.11 & 57.57 & 88.02 & 69.61 \\
\hline S8 & 84.26 & 96.31 & 89.88 & 99.23 & 93.73 & 96.40 & 86.60 & 68.30 & 76.37 & 58.82 & 86.78 & 70.12 \\
\hline S9 & 85.51 & 96.61 & 90.72 & 99.05 & 93.43 & 96.16 & 87.46 & 70.10 & 77.83 & 57.97 & 87.19 & 69.64 \\
\hline S10 & 85.51 & 96.61 & 90.72 & $99 ., 15$ & 94.07 & 96.54 & 86.52 & 71.13 & 78.08 & 60.35 & 85.54 & 70.77 \\
\hline S11 & 93.23 & 97.49 & 95.31 & 99.35 & 97.65 & 98.49 & 90.26 & 81.19 & 85.48 & 75.17 & 90.08 & 81.95 \\
\hline $\mathrm{S} 12$ & 93.00 & 97.94 & 95.40 & 99.35 & 97.70 & 98.52 & 91.74 & 80.15 & 85.56 & 74.83 & 90.91 & 82.09 \\
\hline S13 & 91.15 & 97.20 & 94.08 & 99.19 & 93.64 & 96.34 & 91.22 & 82.99 & 86.91 & 58.68 & 88.02 & 70.41 \\
\hline S14 & 91.15 & 97.20 & 94.08 & 99.14 & 93.60 & 96.29 & 92.49 & 82.47 & 87.19 & 58.65 & 89.67 & 70.92 \\
\hline S15 & 94.02 & 97.35 & 95.65 & 99.06 & 94.50 & 96.72 & 90.65 & 82.47 & 86.37 & 59.28 & 88.43 & 70.98 \\
\hline S16 & 93.75 & 97.35 & 95.51 & 99.34 & 95.73 & 97.50 & 90.33 & 84.28 & 87.20 & 66.36 & 89.67 & 76.27 \\
\hline S17 & 92.11 & 96.46 & 94.24 & 99.17 & 96.89 & 98.01 & 89.47 & 83.25 & 86.25 & 71.82 & 86.36 & 78.42 \\
\hline S18 & 92.54 & 96.90 & 94.67 & 99.04 & 96.42 & 97.71 & 90.40 & 82.47 & 86.25 & 67.65 & 85.54 & 75.55 \\
\hline S19 & 91.76 & 96.90 & 94.26 & 99.32 & 93.39 & 96.26 & 89.92 & 82.73 & 86.17 & 57.33 & 88.84 & 69.69 \\
\hline S20 & 90.90 & 97.20 & 93.94 & 99.45 & 93.17 & 96.21 & 91.07 & 81.44 & 85.99 & 56.25 & 89.26 & 69.01 \\
\hline S21 & 91.39 & 97.05 & 94.13 & 99.32 & 93.52 & 96.33 & 91.01 & 83.51 & 87.10 & 57.99 & 88.43 & 70.05 \\
\hline S22 & 90.97 & 96.61 & 93.71 & 99.32 & 93.64 & 96.40 & 90.48 & 83.25 & 86.71 & 58.90 & 88.84 & 70.84 \\
\hline $\mathrm{S} 23$ & 94.95 & 97.05 & 95.99 & 99.09 & 97.99 & 98.54 & 90.61 & 84.54 & 87.47 & 78.85 & 90.91 & 84.45 \\
\hline S24 & 94.70 & 97.49 & 96.08 & 99.27 & 98.12 & 98.69 & 91.11 & 84.54 & 87.70 & 78.34 & 89.67 & 83.62 \\
\hline
\end{tabular}




\section{References}

1. Bonan, G.B. Forests and climate change: Forcings, feedbacks, and the climate benefits of forests. Science 2008, 320, 1444-1449. [CrossRef] [PubMed]

2. Li, Q. Forest Bathing: How Trees Can Help You Find Health and Happiness; Viking Press: New York, NY, USA, 2018 ; ISBN 0525559868.

3. WWF. Available online: https://www.worldwildlife.org/industries/responsible-forestry (accessed on 18 December 2021).

4. Zhang, Q.; Ge, L.; Zhang, R.; Metternicht, G.I.; Du, Z.; Kuang, J.; Xu, M. Deep-learning-based burned area mapping using the synergy of Sentinel-1\&2 data. Remote Sens. Environ. 2021, 264, 112575. [CrossRef]

5. Schroeder, W.; Oliva, P.; Giglio, L.; Quayle, B.; Lorenz, E.; Morelli, F. Active fire detection using Landsat-8/OLI data. Remote Sens. Environ. 2016, 185, 210-220. [CrossRef]

6. Palandjian, D.; Gitas, I.Z.; Wright, R. Burned area mapping and post-fire impact assessment in the Kassandra peninsula (Greece) using Landsat TM and Quickbird data. Geocarto Int. 2009, 24, 193-205. [CrossRef]

7. Sertel, E.; Alganci, U. Comparison of pixel and object-based classification for burned area mapping using SPOT-6 images. Geomatics Nat. Hazards Risk 2016, 7, 1198-1206. [CrossRef]

8. Widodo, J.; Sulaiman, A.; Awaluddin, A.; Riyadi, A.; Nasucha, M.; Perissin, D.; Sri Sumantyo, J.T. Application of SAR Interferometry Using ALOS-2 PALSAR-2 Data as Precise Method to Identify Degraded Peatland Areas Related to Forest Fire. Geosciences 2019, 9, 484. [CrossRef]

9. Tanase, M.A.; Santoro, M.; Wegmüller, U.; de la Riva, J.; Pérez-Cabello, F. Properties of X-, C-and L-band repeat-pass interferometric SAR coherence in Mediterranean pine forests affected by fires. Remote Sens. Environ. 2010, 114, 2182-2194. [CrossRef]

10. Philipp, M.B.; Levick, S.R. Exploring the potential of C-Band SAR in contributing to burn severity mapping in tropical savanna. Remote Sens. 2020, 12, 49. [CrossRef]

11. Xulu, S.; Mbatha, N.; Peerbhay, K. Burned Area Mapping over the Southern Cape Forestry Region, South Africa Using Sentinel Data within GEE Cloud Platform. ISPRS Int. J. Geo-Inf. 2021, 10, 511. [CrossRef]

12. Viedma, O.; Moreno, J.M.; Güngöroglu, C.; Cosgun, U.; Kavgac1, A. Recent land-use and land-cover changes and its driving factors in a fire-prone area of southwestern Turkey. J. Environ. Manag. 2017, 197, 719-731. [CrossRef]

13. Elhag, M.; Yimaz, N.; Bahrawi, J.; Boteva, S. Evaluation of optical remote sensing data in burned areas mapping of Thasos Island, Greece. Earth Syst. Environ. 2020, 4, 813-826. [CrossRef]

14. Thompson, M.P.; MacGregor, D.G.; Dunn, C.J.; Calkin, D.E.; Phipps, J. Rethinking the wildland fire management system. J. For. 2018, 116, 382-390. [CrossRef]

15. Koutsias, N.; Karteris, M. Burned area mapping using logistic regression modeling of a single post-fire Landsat-5 Thematic Mapper image. Int. J. Remote Sens. 2000, 21, 673-687. [CrossRef]

16. Pereira, A.A.; Libonati, R.; Rodrigues, J.A.; Nogueira, J.; Santos, F.L.M.; Oom, D.; Sanches, W.; Alvarado, S.T.; Pereira, J. Multi-sensor, active fire-supervised, one-class burned area mapping in the brazilian savanna. Remote Sens. 2021, 13, 4005. [CrossRef]

17. Sali, M.; Piaser, E.; Boschetti, M.; Brivio, P.A.; Sona, G.; Bordogna, G.; Stroppiana, D. A Burned Area Mapping Algorithm for Sentinel-2 Data Based on Approximate Reasoning and Region Growing. Remote Sens. 2021, 13, 2214. [CrossRef]

18. Matc1, D.K.; Avdan, U. Comparative analysis of unsupervised classification methods for mapping burned forest areas. Arab. J. Geosci. 2020, 13, 711. [CrossRef]

19. Smiraglia, D.; Filipponi, F.; Mandrone, S.; Tornato, A.; Taramelli, A. Agreement index for burned area mapping: Integration of multiple spectral indices using Sentinel-2 satellite images. Remote Sens. 2020, 12, 1862. [CrossRef]

20. Quintano, C.; Fernández-Manso, A.; Fernández-Manso, O.; Shimabukuro, Y.E. Mapping burned areas in Mediterranean countries using spectral mixture analysis from a uni-temporal perspective. Int. J. Remote Sens. 2006, 27, 645-662. [CrossRef]

21. Kasischke, E.S.; French, N.H.F.; Harrell, P.; Christensen, N.L., Jr.; Ustin, S.L.; Barry, D. Monitoring of wildfires in boreal forests using large area AVHRR NDVI composite image data. Remote Sens. Environ. 1993, 45, 61-71. [CrossRef]

22. Santana, N.C.; de Carvalho Júnior, O.A.; Gomes, R.A.T.; Guimarães, R.F. Burned-area detection in Amazonian environments using standardized time series per pixel in MODIS data. Remote Sens. 2018, 10, 1904. [CrossRef]

23. Liu, S.; Wang, S.; Chi, T.; Wen, C.; Wu, T.; Wang, D. An improved combined vegetation difference index and burn scar index approach for mapping cropland burned areas using combined data from Landsat 8 multispectral and thermal infrared bands. Int. J. Wildl. Fire 2020, 29, 499-512. [CrossRef]

24. Mashhadi, N.; Alganci, U. Determination of forest burn scar and burn severity from free satellite images: A comparative evaluation of spectral indices and machine learning classifiers. Int. J. Environ. Geoinform. 2021, 8, 488-497. [CrossRef]

25. Smith, A.M.S.; Drake, N.A.; Wooster, M.J.; Hudak, A.T.; Holden, Z.A.; Gibbons, C.J. Production of Landsat ETM+ reference imagery of burned areas within Southern African savannahs: Comparison of methods and application to MODIS. Int. J. Remote Sens. 2007, 28, 2753-2775. [CrossRef]

26. Martín, M.P.; Gómez, I.; Chuvieco, E. Burnt Area Index (BAIM) for burned area discrimination at regional scale using MODIS data. For. Ecol. Manag. 2006, 234, S221. [CrossRef]

27. Pinty, B.; Verstraete, M.M. GEMI: A non-linear index to monitor global vegetation from satellites. Vegetatio 1992, 101, 15-20. [CrossRef]

28. Trigg, S.; Flasse, S. An evaluation of different bi-spectral spaces for discriminating burned shrub-savannah. Int. J. Remote Sens. 2001, 22, 2641-2647. [CrossRef] 
29. Miller, J.D.; Thode, A.E. Quantifying burn severity in a heterogeneous landscape with a relative version of the delta Normalized Burn Ratio (dNBR). Remote Sens. Environ. 2007, 109, 66-80. [CrossRef]

30. Mallinis, G.; Mitsopoulos, I.; Chrysafi, I. Evaluating and comparing sentinel 2A and landsat-8 operational land imager (OLI) spectral indices for estimating fire severity in a Mediterranean pine ecosystem of Greece. GISci. Remote Sens. 2018, 55, 1-18. [CrossRef]

31. Achour, H.; Toujani, A.; Trabelsi, H.; Jaouadi, W. Evaluation and comparison of Sentinel-2 MSI, Landsat 8 OLI, and EFFIS data for forest fires mapping. Illustrations from the summer 2017 fires in Tunisia. Geocarto Int. 2021, 36, 1-20. [CrossRef]

32. Ban, Y.; Zhang, P.; Nascetti, A.; Bevington, A.R.; Wulder, M.A. Near real-time wildfire progression monitoring with Sentinel-1 SAR time series and deep learning. Sci. Rep. 2020, 10, 1322. [CrossRef] [PubMed]

33. Stroppiana, D.; Azar, R.; Calò, F.; Pepe, A.; Imperatore, P.; Boschetti, M.; Silva, J.; Brivio, P.A.; Lanari, R. Integration of optical and SAR data for burned area mapping in Mediterranean Regions. Remote Sens. 2015, 7, 1320-1345. [CrossRef]

34. Filipponi, F. Exploitation of sentinel-2 time series to map burned areas at the national level: A case study on the 2017 italy wildfires. Remote Sens. 2019, 11, 622. [CrossRef]

35. Chuvieco, E.; Lizundia-Loiola, J.; Pettinari, M.L.; Ramo, R.; Padilla, M.; Tansey, K.; Mouillot, F.; Laurent, P.; Storm, T.; Heil, A. Generation and analysis of a new global burned area product based on MODIS $250 \mathrm{~m}$ reflectance bands and thermal anomalies. Earth Syst. Sci. Data 2018, 10, 2015-2031. [CrossRef]

36. Giglio, L.; Boschetti, L.; Roy, D.P.; Humber, M.L.; Justice, C.O. The Collection 6 MODIS burned area mapping algorithm and product. Remote Sens. Environ. 2018, 217, 72-85. [CrossRef]

37. Fernández-Manso, A.; Quintano, C. A synergetic approach to burned area mapping using maximum entropy modeling trained with hyperspectral data and VIIRS hotspots. Remote Sens. 2020, 12, 858. [CrossRef]

38. Otón, G.; Ramo, R.; Lizundia-Loiola, J.; Chuvieco, E. Global detection of long-term (1982-2017) burned area with AVHRR-LTDR data. Remote Sens. 2019, 11, 2079. [CrossRef]

39. Roy, D.P.; Huang, H.; Boschetti, L.; Giglio, L.; Yan, L.; Zhang, H.H.; Li, Z. Landsat-8 and Sentinel-2 burned area mapping-A combined sensor multi-temporal change detection approach. Remote Sens. Environ. 2019, 231, 111254. [CrossRef]

40. Ngadze, F.; Mpakairi, K.S.; Kavhu, B.; Ndaimani, H.; Maremba, M.S. Exploring the utility of Sentinel-2 MSI and Landsat 8 OLI in burned area mapping for a heterogenous savannah landscape. PLoS ONE 2020, 15, e0232962. [CrossRef]

41. Moreira, A.; Prats-Iraola, P.; Younis, M.; Krieger, G.; Hajnsek, I.; Papathanassiou, K.P. A tutorial on synthetic aperture radar. IEEE Geosci. Remote Sens. Mag. 2013, 1, 6-43. [CrossRef]

42. Tariq, A.; Shu, H.; Li, Q.; Altan, O.; Khan, M.R.; Baqa, M.F.; Lu, L. Quantitative Analysis of Forest Fires in Southeastern Australia Using SAR Data. Remote Sens. 2021, 13, 2386. [CrossRef]

43. Donezar, U.; De Blas, T.; Larrañaga, A.; Ros, F.; Albizua, L.; Steel, A.; Broglia, M. Applicability of the multitemporal coherence approach to sentinel-1 for the detection and delineation of burnt areas in the context of the copernicus emergency management service. Remote Sens. 2019, 11, 2607. [CrossRef]

44. Verhegghen, A.; Eva, H.; Ceccherini, G.; Achard, F.; Gond, V.; Gourlet-Fleury, S.; Cerutti, P.O. The potential of Sentinel satellites for burnt area mapping and monitoring in the Congo Basin forests. Remote Sens. 2016, 8, 986. [CrossRef]

45. Belenguer-Plomer, M.A.; Tanase, M.A.; Chuvieco, E.; Bovolo, F. CNN-based burned area mapping using radar and optical data. Remote Sens. Environ. 2021, 260, 112468. [CrossRef]

46. General Directorate of Forestry, OGM 2020. ISBN 978-605-7599-68-1. Available online: https://www.ogm.gov.tr/tr/ ormanlarimiz/Turkiye-Orman-Varligi (accessed on 28 December 2021). (In Turkish)

47. Mauri, A.; Di Leo, M.; de Rigo, D.; Caudullo, G. Pinus Halepensis and Pinus Brutia in Europe: Distribution, Habitat, Usage and Threats; San-Miguel-Ayanz, J., de Rigo, D., Caudullo, G., Houston Durrant, T., Mauri, A., Eds.; European Atlas of Forest Tree Species; Publications Office of the EU: Luxembourg, 2016; p. e0166b8.

48. Kaynaş, B.Y.; Öney Birol, S. Afforestation of post-fire Pinus brutia Ten forests Effects of Eucalyptus camaldulensis Dehnh P brutia and Pinus pinea L leaf extracts on cell division in P brutia seeds. Allelopathy J. 2020, 49, 125-140. [CrossRef]

49. Chambel, M.R.; Climent, J.; Pichot, C.; Ducci, F. Chapter 5: Mediterranean pines (Pinus halepensis Mill. and brutia Ten.). In Forest Tree Breeding in Europe; Managing Forest Ecosystems 25; Springer: Dordrecht, The Netherlands, 2013; pp. 229-265. [CrossRef]

50. Dailysabah. Available online: https://www.dailysabah.com/opinion/op-ed/fires-floods-mucilage-whats-happening-in-turkey (accessed on 20 December 2021).

51. San-Miguel-Ayanz, J.; Durrant, T.; Boca, R.; Maianti, P.; Liberta, G.; Artes-Vivancos, T.; Oom, D.; Branco, A.; de Rigo, D.; Ferrari, D.; et al. Forest Fires in Europe, Middle East and North Africa 2019, EUR 30402 EN; Publications Office of the European Union: Luxembourg, 2020; ISBN 978-92-76-23209-4. [CrossRef]

52. San-Miguel-Ayanz, J.; Durrant, T.; Boca, R.; Maianti, P.; Liberta, G.; Artes-Vivancos, T.; Oom, D.; Branco, A.; de Rigo, D.; Ferrari, D. Forest Fires in Europe, Middle East and North Africa 2020, EUR 30862 EN; Publications Office of the European Union: Luxembourg, 2021; ISBN 978-92-76-42351-5. [CrossRef]

53. Reuters. Available online: https://www.reuters.com/world/middle-east/fire-near-turkish-power-plant-under-control-localmayor-2021-08-04/ (accessed on 20 December 2021).

54. Atak, B.K.; Tonyaloğlu, E.E. Evaluating spectral indices for estimating burned areas in the case of Izmir/Turkey. Eurasian J. For. Sci. 2020, 8, 49-59. [CrossRef] 
55. Veraverbeke, S.; Lhermitte, S.; Verstraeten, W.W.; Goossens, R. Evaluation of pre/post-fire differenced spectral indices for assessing burn severity in a Mediterranean environment with Landsat Thematic Mapper. Int. J. Remote Sens. 2011, 32, $3521-3537$. [CrossRef]

56. Miller, J.D.; Knapp, E.E.; Key, C.H.; Skinner, C.N.; Isbell, C.J.; Creasy, R.M.; Sherlock, J.W. Calibration and validation of the relative differenced Normalized Burn Ratio (RdNBR) to three measures of fire severity in the Sierra Nevada and Klamath Mountains, California, USA. Remote Sens. Environ. 2009, 113, 645-656. [CrossRef]

57. Veraverbeke, S.; Lhermitte, S.; Verstraeten, W.W.; Goossens, R. The temporal dimension of differenced Normalized Burn Ratio (dNBR) fire/burn severity studies: The case of the large 2007 Peloponnese wildfires in Greece. Remote Sens. Environ. 2010, 114, 2548-2563. [CrossRef]

58. Key, C.H.; Benson, N.C. Landscape Assessment: Remote Sensing of Severity, the Normalized Burn Ratio and Ground Measure of Severity, the Composite Burn Index; FIREMON: Fire Effects Monitoring and Inventory System, General Technical Report, RMRS-GTR-164CD:LA1-LA51; USDA Forest Service, Rocky Mountain Research Station: Ogden, UT, USA, 2005.

59. Key, C.H.; Benson, N.C. Measuring and remote sensing of burn severity. In Proceedings of the Joint Fire Science Conference and Workshop; University of Idaho and International Association of Wildland Fire: Boise, ID, USA, 1999; Volume 2, p. 284.

60. Qin, Z.; Karnieli, A.; Berliner, P. A mono-window algorithm for retrieving land surface temperature from Landsat TM data and its application to the Israel-Egypt border region. Int. J. Remote Sens. 2001, 22, 3719-3746. [CrossRef]

61. Sobrino, J.A.; Jiménez-Muñoz, J.C.; Sòria, G.; Romaguera, M.; Guanter, L.; Moreno, J.; Plaza, A.; Martínez, P. Land surface emissivity retrieval from different VNIR and TIR sensors. IEEE Trans. Geosci. Remote Sens. 2008, 46, 316-327. [CrossRef]

62. Sekertekin, A.; Bonafoni, S. Land surface temperature retrieval from Landsat 5, 7, and 8 over rural areas: Assessment of different retrieval algorithms and emissivity models and toolbox implementation. Remote Sens. 2020, 12, 294. [CrossRef]

63. Hagberg, J.O.; Ulander, L.M.H.; Askne, J. Repeat-pass SAR interferometry over forested terrain. IEEE Trans. Geosci. Remote Sens. 1995, 33, 331-340. [CrossRef]

64. Abdikan, S.; Bayik, C.; Ustuner, M.; Sanli, F.B. Repeat-pass interferometric and backscatter analysis of X-band PAZ satellite-first results. Int. Arch. Photogramm. Remote Sens. Spat. Inf. Sci. 2020, 43, 253-258. [CrossRef]

65. SNAP v8.0. Available online: http:/ / step.esa.int (accessed on 14 December 2021).

66. Shao, Z.; Sumari, N.S.; Portnov, A.; Ujoh, F.; Musakwa, W.; Mandela, P.J. Urban sprawl and its impact on sustainable urban development: A combination of remote sensing and social media data. Geo-Spat. Inf. Sci. 2021, 24, 241-255. [CrossRef]

67. Breiman, L. Random forests. Mach. Learn. 2001, 45, 5-32. [CrossRef]

68. Ok, A.O.; Akar, O.; Gungor, O. Evaluation of random forest method for agricultural crop classification. Eur. J. Remote Sens. 2012, 45, 421-432. [CrossRef]

69. Van der Linden, S.; Rabe, A.; Held, M.; Jakimow, B.; Leitão, P.J.; Okujeni, A.; Schwieder, M.; Suess, S.; Hostert, P. The EnMAP-BoxA toolbox and application programming interface for EnMAP data processing. Remote Sens. 2015, 7, 11249-11266. [CrossRef]

70. EnMAP-Box Developers. EnMAP-Box 3-A QGIS Plugin to Process and Visualize Hyperspectral Remote Sensing Data. 2019. Available online: https:/ / enmap-box.readthedocs.io (accessed on 8 December 2021).

71. QGIS. Available online: http://www.qgis.org (accessed on 12 December 2021).

72. Foody, G.M. Status of land cover classification accuracy assessment. Remote Sens. Environ. 2002, 80, 185-201. [CrossRef]

73. Ustuner, M.; Balik Sanli, F. Polarimetric Target Decompositions and Light Gradient Boosting Machine for Crop Classification: A Comparative Evaluation. ISPRS Int. J. Geo-Inf. 2019, 8, 97. [CrossRef]

74. Tadono, T.; Ishida, H.; Oda, F.; Naito, S.; Minakawa, K.; Iwamoto, H. Precise global DEM generation by ALOS PRISM. ISPRS Ann. Photogramm. Remote Sens. Spat. Inf. Sci. 2014, 2, 71-76. [CrossRef]

75. Quintano, C.; Fernández-Manso, A.; Fernández-Manso, O. Combination of Landsat and Sentinel-2 MSI data for initial assessing of burn severity. Int. J. Appl. Earth Obs. Geoinf. 2018, 64, 221-225. [CrossRef]

76. Nasery, S.; Kalkan, K. Burn area detection and burn severity assessment using Sentinel 2 MSI data: The case of Karabağlar district, İzmir/Turkey. Turk. J. Geosci. 2020, 1, 72-77. 